\title{
'Primary' pulmonary hypertension, eosinophilia, and filariasis in Ceylon
}

\author{
Ivor Obeyesekere and Neil de Soysa \\ From the Department of Cardiology, General Hospital, Colombo, Ceylon
}

\begin{abstract}
'Primary' pulmonary hypertension, which is rare in western countries, was found to be relatively common in Ceylon.
\end{abstract}

The clinical and haemodynamic features were studied. There were two distinct types of the disease, malignant and benign. Patients with the malignant form of the disease had a rapidly progressive illness of short duration and an invariably fatal outcome. Those with the benign form gave a long history and, in spite of severe pulmonary hypertension, were only slightly disabled. They seemed to tolerate the disease better. An important factor which determined the clinical course of the disease was the patency of the foramen ovale. This appeared to act as a safety valve permitting a right-to-left shunt in times of stress. The foramen ovale was closed in all patients with the malignant type. The therapeutic implications of this need further study.

Many patients with 'primary' pulmonary hypertension had an unusually high eosinophil count (normal range for Ceylon, 0-500 per cu.mm.). Patients in hospitals often have higher counts ranging from 0-1000 per cu.mm. due to intestinal parasitic infestation. Patients with 'primary' pulmonary hypertension were found to have a significantly higher mean eosinophil count than age-matched, sex-matched controls admitted to the Cardiology Unit with chronic rheumatic heart disease and congenital heart disease. The higher count was not due to intestinal parasitic infestation, and none of the other known causes of a raised eosinophil count were present.

Four patients had eosinophil counts over 3,000 per cu.mm., the range commonly associated with tropical pulmonary eosinophilia, a disease caused by filariasis. These patients did not manifest any of the symptoms of tropical pulmonary eosinophilia. Patients with 'primary' pulmonary hypertension were examined for evidence of filariasis (clinical, haematological, and serological). Volunteers from among patients with tropical pulmonary eosinophilia and symptom-free patients positive for Wuchereria bancrofti microfilaria were similarly tested and also catheterized for evidence of pulmonary hypertension. The results of these investigations and their significance are discussed. The geographical incidence of 'primary' pulmonary hypertension and filariasis was similar.

Filarial worms are known to cause pulmonary hypertension in animals. There is sufficient evidence to suspect that the same may be true in humans. This may explain the high incidence of the disease in Ceylon and its unusually high prevalence among men.

'Primary' pulmonary hypertension has been defined as a disease of unknown aetiology, where the increased pulmonary artery pressure occurs in the absence of any recognizable lesion in the heart or pulmonary parenchyma.

This paper describes the clinical features seen in 30 such patients investigated in the Cardiology Unit, General Hospital, Colombo. In I957, Wade and Ball suggested that 'unexplained pulmonary hypertension' might Received 2 February 1970. not be homogeneous clinically or pathologically. We examined the possibility of the disease being different from that hitherto described in temperate climates. We wish to report the high incidence of the disease in Ceylon with men and women almost equally affected. An association with eosinophilia was examined. The relation of different aetiological agents peculiar to the tropics was studied and in particular filariasis as a causative agent. 


\section{Subjects and methods}

The patients included in this study had severe pulmonary hypertension as the only significant cardiovascular disorder. In particular, they did not have congenital left-to-right shunts (intracardiac or extracardiac), organic valvular heart disease, diseases of the left side of the heart which might cause pulmonary hypertension, or pericardial disease. They were free of parenchymatous lung disease (such as emphysema, chronic bronchitis, fibrosis), collagen disease, sarcoid, thoracic deformities, and hypoventilatory disorders. Also excluded were patients with any suspicion of thromboembolic pulmonary hypertension caused by recurrent embolism.

The main clinical features, serial electrocardiograms, phonocardiograms, and chest $x$-ray films were studied. Right heart catheterization was performed and selective angiocardiography done whenever there was a doubt as to the correct diagnosis.

Various blood tests were carried out: examination for LE cells, and antinuclear factor, blood picture studies, anti-streptolysin titres, latex flocculation tests, erythrocyte sedimentation rate, and serum protein levels.

The absolute eosinophil counts in patients with 'primary' pulmonary hypertension were compared with two unrelated groups of patients also admitted to the Cardiology Unit. The controls, matched for age and sex, were from those suffering from chronic rheumatic heart disease and congenital heart disease. Since the commonest cause of a raised eosinophil count in Ceylon is intestinal parasitic infestation, the stools of all three groups were examined for helminth ova.

A past history of filariasis was inquired for, and clinical and haematological evidence of filarial infection looked for. Two serological tests for filarial antibodies, the filarial complement-fixation test (Danaraj, 1957; Danaraj, da Silva, and Schacher, 1957), and the fluorescent antibody test for filarial antibodies (Jayewardena and Wijayaratnam, 1968) were also done on 15 patients. The findings were compared with similar tests performed on two groups of patients known to have a filarial aetiology: (I) symptom-free patients with microfilaria, and (2) patients with tropical pulmonary eosinophilia. The first group consisted of volunteers from areas where filariasis is endemic, where thick blood films were collected from the population during house to house visits at night, and examined for $W$. bancrofti microfilaria and found to be positive. The second group consisted

TABLE I Age-groups and sex of 30 patients suffering from 'primary' pulmonary hypertension

\begin{tabular}{|c|c|c|c|c|c|c|}
\hline \multirow{2}{*}{$\begin{array}{l}\text { Sex of } \\
\text { patient }\end{array}$} & \multicolumn{6}{|c|}{ Age-group (yr.) } \\
\hline & $0-10$ & I I -20 & $21-30$ & $31-40$ & $4 I-50$ & 50 \\
\hline Female (18) & 0 & 5 & 9 & 2 & I & I \\
\hline Male (12) & I & I & 4 & 5 & I & 0 \\
\hline Total & $\mathbf{I}$ & 6 & 13 & 7 & 2 & I \\
\hline
\end{tabular}

of those suffering from tropical pulmonary eosiniphilia attending the General Hospital, Colombo, complaining of cough and wheezing, especially at night, with an absolute eosinophil count over 3,000 per cu.mm. These two groups of control patients were cath eterized, at which time blood samples were withdrawn from the pulmonary artery and examined for microfilariae, and the pulmonary artery pressures were measured.

\section{Results}

Incidence The incidence of 'primary' pulmonary hypertension in a consecutive series of 1000 patients with cardiovascular diseases of all types studied in the Cardiology Unit, General Hospital, Colombo, was 3.7 per cent (37 patients). The first 30 patients provide the material for this paper.

Age and sex distribution (Table $I$ ) There were 18 female and $I 2$ male patients, giving a sex ratio of $1.5: 1$. Their ages ranged from 9 to $6 I ; 26$ were between II and 40 years. Three women were married, and 2 had children.

Clinical features The clinical data are summarized in Appendix II.

There were two distinct types of the disease, malignant and benign.

\section{Malignant type}

Eight patients suffered from a malignant form of the disease, the illness being of short duration, less than I year, rapidly progressive, resistant to treatment, and the outcome usually fatal. They were severely disabled; many developed sinus tachycardia, intractable right heart failure, and tricuspid incompetence. Seven patients died within 3 months of being first examined.

\section{Benign type}

Twenty-two patients suffered from a more benign, chronic form of the disease. They gave a long history varying from $I \frac{1}{2}$ to 35 years. Right heart failure was either absent or mild, and response to treatment was usually good. Tricuspid incompetence was present in a few patients. In spite of a considerable degree of pulmonary hypertension, they were only slightly disabled. The disease process appeared to be static or only slowly progressive.

History The symptoms in the two groups were similar, only more severe, more acute in onset, and more rapidly progressive in the malignant type.

The presenting and universal complaint 
was dyspnoea on effort. Effort tolerance was limited to a varying degree by dyspnoea which occurred in all 30 , palpitations in 26 , undue fatigue in 21 , effort syncope in 20 , and angina in 13 . Seven patients complained of a constant praecordial discomfort described as a 'feeling of suffocation', a 'boring pain', and a 'bursting feeling' present both at rest and on effort, while seated and lying down. Fourteen complained of recurrent cough, and 7 of painless haemoptysis. Excessive sweating was a troublesome symptom. All 8 patients with the malignant type had severe dyspnoea, undue fatigue, effort syncope and angina, and in the later stages were extremely distressed even when lying still in bed.

There was no past history of leg vein thrombosis, trauma to lower limbs, or pelvic operations. Eight patients gave a past history of undiagnosed febrile illnesses associated with severe joint and muscle pain. Two gave histories of clinical filariasis: funiculitis in Case 17, lymphangitis in Case 15. Three gave histories of tropical pulmonary eosinophilia. Case I underwent a thorocatomy in 1960 for repair of a suspected atrial septal defect. At operation she was found to be suffering from 'primary' pulmonary hypertension confirmed by lung biopsy. Case 19 was examined by one of us (I.O.) in 1958 when pulmonary hypertension was diagnosed. Case $14^{1}$ in 1964 and Case $2^{2}$ in 1963 were independently investigated in different hospitals and diagnosed as suffering from 'primary' pulmonary hypertension.

The patients ate a well-balanced diet, there was no incriminating substance which could have caused the disease, nor was there a familial history of this disease.

Clinical examination The clinical picture was dominated by signs of right ventricular hypertrophy and pulmonary hypertension, complicated in some instances by congestive cardiac failure and tricuspid incompetence. In the malignant type right heart failure, tricuspid incompetence, and sinus tachycardia were usually present. Many of the patients were underweight.

Cyanosis, clubbing of fingers, and mild polycythaemia were unusual but occurred in a few patients with severe pulmonary hypertension as a late manifestation, probably due to a right-to-left shunt across a patent foramen ovale. This did not occur in patients with the malignant type in all of whom the

\footnotetext{
1 Case 14 was investigated by Professor John Goodwin at the Royal Postgraduate Medical School, London.

${ }^{2}$ Case 2 was investigated at the Christian Hospital, Vellore, India.
}

foramen ovale was closed. Cyanosis without clubbing occurred in the presence of severe right heart failure and was probably due to a wide arteriovenous difference and arterial desaturation, and disappeared when the failure was corrected. All patients were in sinus rhythm, the pulse volume usually small. Jugular venous pressure was often strikingly raised. The systemic blood pressure and pulse pressure were often low. The cardiac impulse was characterized by a powerful right ventricular heave, maximal between the left sternal edge and mid-clavicular line. A palpable lift was present in the right ventricular outflow tract and closure of the pulmonary valve was palpable. The auscultatory signs confirmed by phonocardiography are summarized in Fig. I. Over the pulmonary area: in 3 patients there was narrow splitting of the second sound with accentuation of the second component; in 15 there was in addition a systolic click, in 5 this was accompanied by a short ejection systolic murmur; in 5 there were both a loud ejection systolic murmur and an early diastolic murmur; finally, in 2 the signs were overshadowed by a very loud pulmonary diastolic murmur, systole being extremely short with the systolic click buried in the first sound. Two patients had fixed splitting of the second sound. Over the tricuspid area: in 12 there was a prominent right atrial gallop and in 9 a pansystolic murmur of tricuspid incompetence.

Course and prognosis There was a remarkable difference in the course and prognosis in the two types.

In the benign type, patients gave a long history ranging from $I \frac{1}{2}$ to 35 years, and, in spite of severe pulmonary hypertension found at the time of cardiac catheterization, they were surprisingly only mildly restricted. Many continued to lead useful lives; some were employed. For instance, Case 25 with a pulmonary artery pressure of 220/112 mm.Hg, continues his occupation as a school teacher. Case 24 with a pressure of $120 / 56 \mathrm{~mm} . \mathrm{Hg}$ worked as a tractor driver till admission to hospital; Case 6 with a pressure of $120 / 60$ $\mathrm{mm} . \mathrm{Hg}$ works as a stenographer. These patients appear to have come to terms with their disease. The only death in this group followed cardiac catheterization.

Eight patients, who belonged to the malignant type, gave a short history under one year, with rapid progressive deterioration. Seven died within a few months of being first seen. Deaths were quite sudden, possibly as a result of an arrhythmia, either atrial fibrillation or an atrioventricular conduction defect. 
TABLE 2 Electrocardiographic data in 30 patients suffering from 'primary' pulmonary hypertension

\begin{tabular}{llc}
\hline & $\begin{array}{l}\text { No. of } \\
\text { patients }\end{array}$ & $\begin{array}{l}\text { Per } \\
\text { cent }\end{array}$ \\
\hline Sinus rhythm & 30 & 100 \\
Electrical axis & & \\
90-I IO & 15 & 50 \\
Over I IO & 15 & 50 \\
Right atrial enlargement & & \\
$\quad$ (p over 2.5 mm.) & 17 & 56.6 \\
Right ventricular hypertrophy & & \\
Grade I & I & 3.3 \\
$\quad$ Grade II & 5 & 16.6 \\
$\quad$ Grade III & 15 & 50 \\
$\quad$ Grade IV & 7 & 23.3 \\
Complete right bundle-branch block & 2 & 6.6 \\
\hline
\end{tabular}

The surviving patient continues to be very ill with sinus tachycardia, gross tricuspid incompetence, and right heart failure. All patients with 'primary' pulmonary hypertension reacted badly to chest infections, and became very breathless and cyanosed during these episodes. They are poor surgical risks and tolerate cardiac catheterization poorly.

Electrocardiograms The electrocardiograms were abnormal in all patients, and are described in Table 2.

They were all in sinus rhythm, with an electrical axis over 90 degrees; 56.6 per cent had right atrial enlargement. Varying degrees of right ventricular hypertrophy or complete right bundle-branch block were present in all. In Table 2 right ventricular hypertrophy was graded according to Hollister and Goodwin (1963).

Radiology of the heart Radiological studies were carried out in each patient and consisted of postero-anterior chest films with cardiac screening. The aorta was small, there was considerable dilatation of the pulmonary artery and main branches, with pruning of the peripheral vessels. There was variable enlargement of the right ventricle and right atrium; the left ventricle and left atrium were small. The peripheral lung fields were unremarkable. The average cardiothoracic ratio was 0.59 (range $0.46-0.93$ ). At fluoroscopy hilar pulsation was conspicuously absent and confirmed the absence of any left atrial enlargement. Cine-angiocardiograms were made in 9 patients. This procedure carried the risk of inducing collapse and ventricular standstill. It was, therefore, performed only where an atrial septal defect or other congenital anomaly was suspected. Angiocardiography confirmed the absence of any shunts from the right chambers of the heart and excluded per-

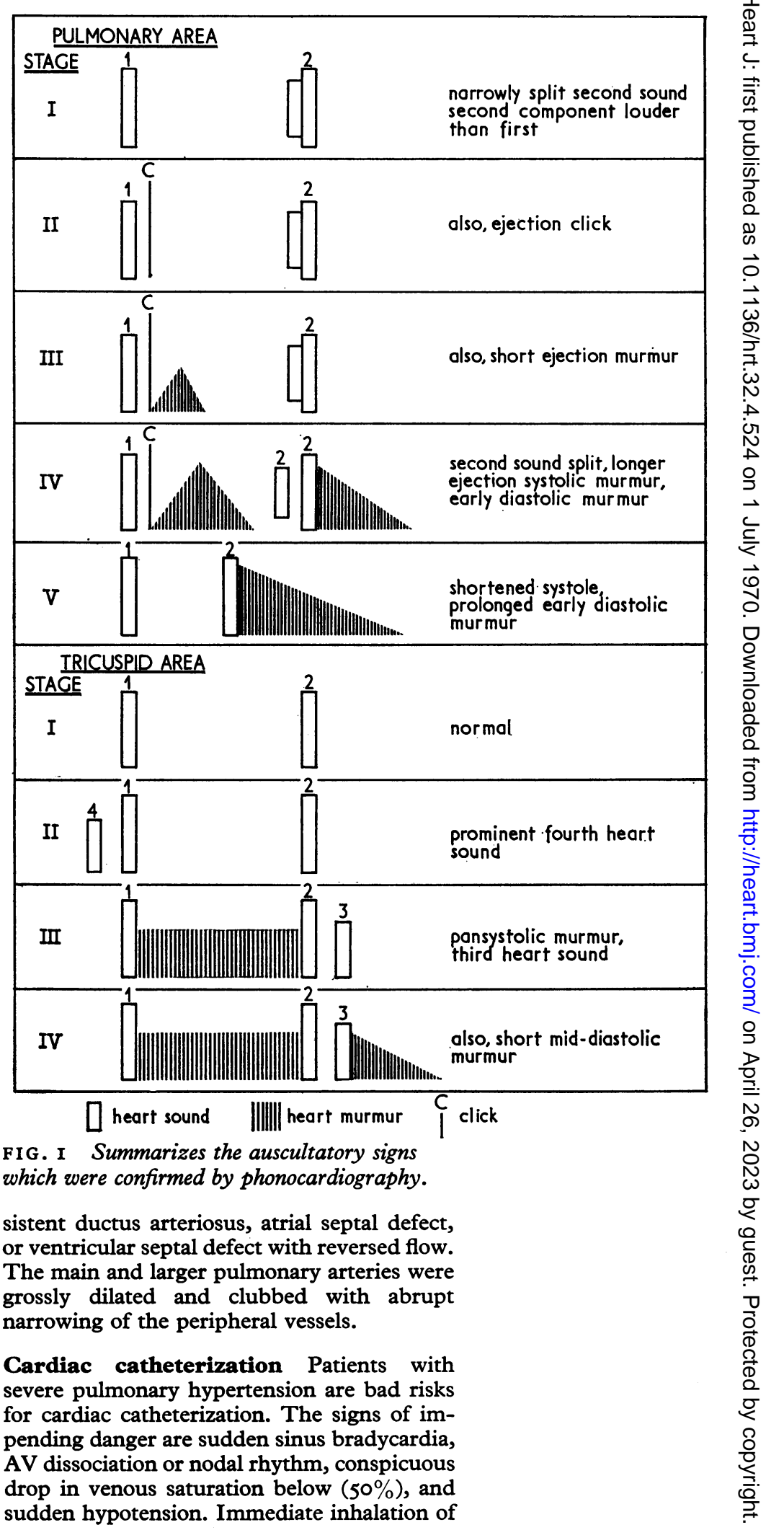


100 per cent oxygen and intracardiac atropine, or small doses of isoprenaline via a cardiac catheter, already in situ, averted certain death in 4 patients.

The catheter data obtained from individual patients are given in Appendix I. In summary, there were no shunts at any level and no significant gradients across the pulmonary valve. The pulmonary systolic blood pressure and the right ventricular pressures were raised; over $100 \mathrm{~mm} . \mathrm{Hg}$ in $2 \mathrm{I}$, and between 80 and $100 \mathrm{~mm} . \mathrm{Hg}$ in 8 . The pulmonary capillary wedge or left atrial pressures were normal. The right atrial pressures were raised. The left atrium was entered through a patent foramen ovale in 12 patients suffering from the benign type of the disease. In no instance of the malignant type was the septum crossed. The arterial oxygen saturation was low: average 89 per cent (range $79-97 \%$ ). The venous oxygen saturation was often abnormally low, with an increased AV oxygen difference which averaged 29 per cent (range II $-44 \%$ ).

Cardiac output averaged $3.7 \mathrm{l} . / \mathrm{min}$. (range $2 \cdot 1-5)$ in 25 patients. Pulmonary vascular resistance (normal I-2.5 units) was extremely high, and averaged 20.4 units (range 13-44) in 23 patients.

A conspicuous feature was the severity of the pulmonary hypertension which was severe in every patient (over $80 \mathrm{~mm} . \mathrm{Hg}$ ). Ten patients had pulmonary artery pressures at or above normal systemic artery levels (systolic pressure, $120 \mathrm{~mm} . \mathrm{Hg}$ ). One patient (Case 25) had the extremely high pressure of $220 / 112$ mm.Hg.

\section{Blood studies}

The average haemoglobin level was I3.I g./100 ml. (range 9.1-17.5). Seven patients were mildly polycythaemic, with haemoglobin levels over $14.6 \mathrm{~g}$. $/ 100 \mathrm{ml}$.

The erythrocyte sedimentation rate, done in all 30 , was normal in 26 . In 4 it was slightly raised with readings in the first hour between IO and 20. The plasma proteins were normal in all, total serum protein averaged 7.6 g./100 $\mathrm{ml}$. (range $6.5-9.0$ ); serum albumin, mean $4.39 \mathrm{~g} . / 100 \mathrm{ml}$. (range $3.5-5.1$ ); serum globulin, mean $3.4 \mathrm{~g}$./100 ml. (range $2 \cdot \mathrm{I}-4 \cdot \mathrm{I}$ ).

Blood for antinuclear factor was negative in the Io patients examined. Anti-streptolysin titre was within normal limits in ro patients examined, and the latex flocculation test negative in 8. The mean serum cholesterol in ro patients was $201 \mathrm{mg}$. $/ 100 \mathrm{ml}$. (range 166250). There was no evidence of any blood dyscrasia in the blood-picture studies. Many patients showed an increase in mature esoinophils. Absolute eosinophil counts were, there-

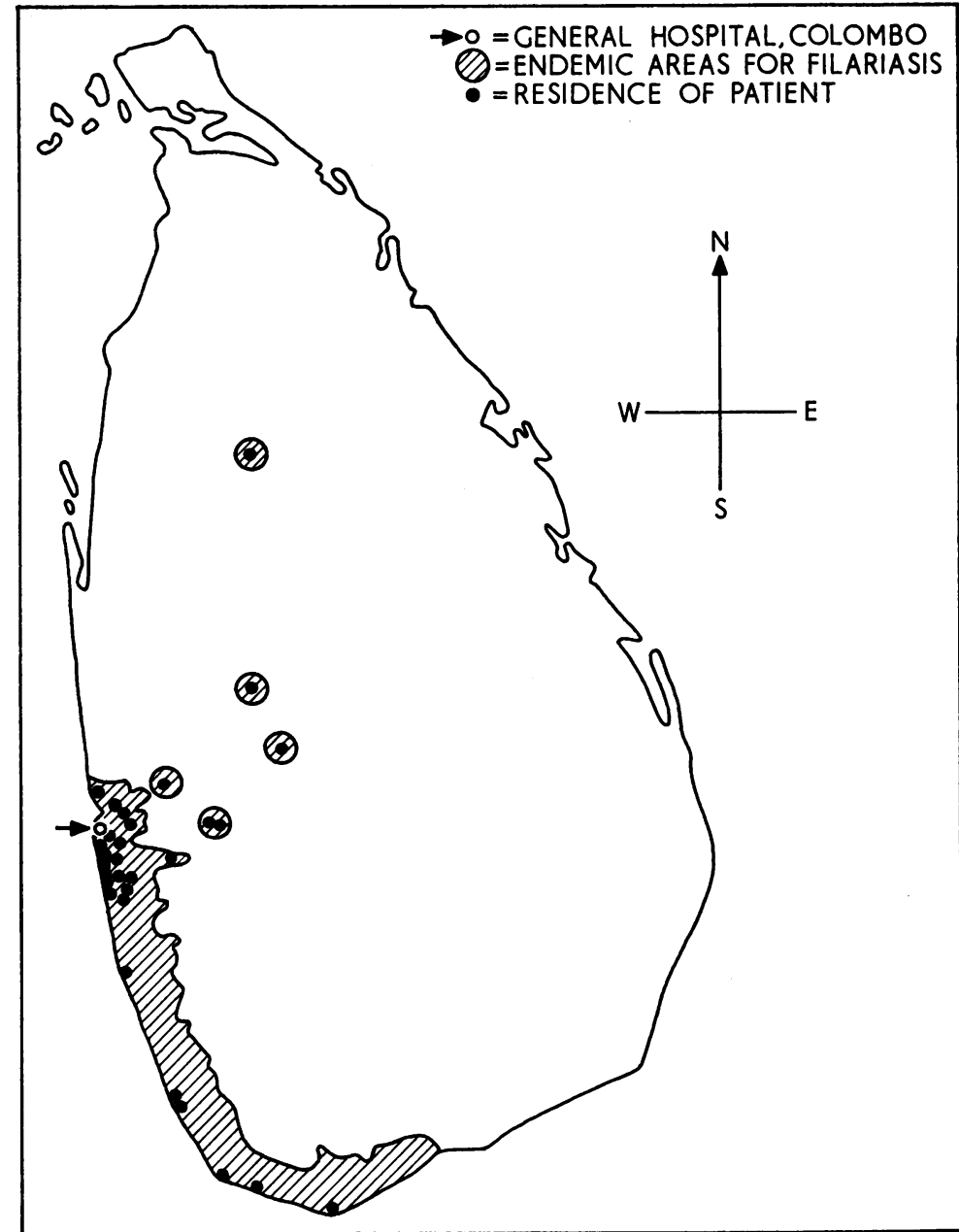

FIG. 2 Map of Ceylon, showing endemic areas for filariasis.

fore, done in all these patients, and compared with similar counts obtained from patients of the same age and sex suffering from chronic rheumatic heart disease and congenital heart disease, the latter serving as controls.

Absolute eosinophil counts (Table 3). The normal range for Ceylonese patients is o-500 per cu.mm.; over 3,000 is considered to indicate tropical pulmonary eosinophilia. The patients with 'primary' pulmonary hypertension and the control groups were therefore grouped under $0-500,501-3,000$, and over $3,000 / \mathrm{cu} . \mathrm{mm}$.

The mean eosinophil count of the patients was I,689 per cu.mm. (range I I 8-9,898). The mean for controls with chronic rheumatic heart disease was 659/cu. mm. (range o-2432), and for congenital heart disease $564 / \mathrm{cu}$. $\mathrm{mm}$. (range 62-1820). There was a significant 
difference between the means of 'primary' pulmonary hypertension compared with chronic rheumatic heart disease $(p=0.025-$ $0.01)$ and congenital heart disease $(p=0.01-$ 0.005 ). There was no significant difference between the means of chronic rheumatic heart disease and congenital heart disease.

Examination of stools Since the commonest cause of a high eosinophil count in Ceylon is intestinal helminth infestation, the stools of patients and both control groups were examined to determine the cause for the conspicuous difference in the eosinophil counts. There was no significant difference. If anything the patients with 'primary' pulmonary hypertension had less severe infestation than the controls.

Tests for filariasis The patients were examined for evidence of filarial infection. Simultaneously the same tests were carried out on two control groups of patients: (a) those with symptom-free microfilaria, and (b) those suffering from tropical pulmonary eosinophilia. The haemoglobin percentages, erythrocyte sedimentation rates, and pulmonary artery pressures were also compared (Appendix III).

A careful search was made for microfilaria in the blood using thick films made from finger blood collected both during the day and night, venous blood collected during the day and night, and pulmonary artery blood collected during cardiac catheterization. They were negative in all patients with 'primary' pulmonary hypertension and tropical pulmonary eosinophilia, and positive in patients with symptom-free microfilaria.

The filaria complement-fixation test (FCFT) was positive in 9 out of 15 patients $(60 \%)$ with 'primary' pulmonary hypertension, 8 out of 8 (100\%) with tropical pulmonary eosinophilia, and I out of 8 (12.5\%) with symptom-free microfilaria. The fluorescent antibody test (FAT) was positive in 3 out of 15 patients $(20 \%)$ with 'primary' pulmonary hypertension, 3 out of $6(50 \%)$ with tropical pulmonary eosinophilia, and in none of $8(0 \%)$ with symptom-free microfilaria.

Either FCFT or FAT was positive in 12 out of $15(80 \%)$ patients with 'primary' pulmonary hypertension; both tests were positive in one.

The pulmonary artery pressures were normal in patients with tropical pulmonary eosinophilia and symptom-free microfilaria.

Epidemiology Parasitological investigations which have been carried out in Ceylon since 1947 have revealed that $W$. bancrofti
TABLE 3 Absolute eosinophil count and stool examination

\begin{tabular}{lllllll}
\hline Disease & \multicolumn{7}{c}{$\begin{array}{l}\text { Absolute eosinophil count } \\
<500\end{array}$} & $500-3000$ & $>3000$ & $\begin{array}{l}\text { Stool examination } \\
H W \text { ova }\end{array}$ & RW ova & $\begin{array}{l}\text { Whipworm } \\
\text { ova }\end{array}$ \\
\hline $\begin{array}{c}\text { 'Primary' pulmonary } \\
\text { hypertension }\end{array}$ & 7 & 19 & 4 & 4 & 1 & 5 \\
$\begin{array}{c}\text { Chronic rheumatic } \\
\text { heart disease }\end{array}$ & 16 & 14 & 0 & 4 & 6 & 4 \\
$\begin{array}{c}\text { Congenital } \\
\text { heart disease }\end{array}$ & 18 & 12 & 0 & 4 & 8 & 2 \\
\hline
\end{tabular}

Two infestations were present in 3 patients with 'primary' pulmonary hypertension; 3 patients with chronic rheumatic heart disease; and 4 patients with congenital heart disease.

\begin{tabular}{lrcl}
\hline & Mean & Standard error & No. of patients \\
\hline 'Primary' pulmonary hypertension & 1689 & $399 \cdot 0$ & 30 \\
Chronic rheumatic heart disease & 659 & $99 \cdot 0$ & 30 \\
Congenital heart disease & 564 & 86.4 & 30
\end{tabular}

Comparison of means of 'primary' pulmonary hypertension with chronic rheumatic heart disease shows a significant difference $(p=0.25-0.01)$.

Comparison of means of 'primary' pulmonary hypertension with congenital heart disease shows a significant difference $(p=0.01-0.005)$.

There is no significant difference between the means of chronic rheumatic heart disease and congestive heart disease.

infection is endemic along the South Western coastal border of the island, and pockets occur in some inland towns (Fig. 2). All 30 patients with 'primary' pulmonary hypertension lived or had lived in these endemic areas.

Pathology Two necropsies were performed: on Case 2, a woman aged 30, who died during cardiac catheterization, and on Case 23, a man aged 2I, who died suddenly in hospital. Case 23 had a strongly positive filaria complementfixation test (titre $I$ in 160 ).

\section{Case 2}

Heart weighed $450 \mathrm{~g}$. and there was considerable hypertrophy of the right ventricle, with dilatation of the right atrium. The thickness of the walls of the four chambers of the heart was as follows: right atrium $4.5 \mathrm{~mm}$., right ventricle $12 \mathrm{~mm}$., left atrium $2 \mathrm{~mm}$., left ventricle $10 \mathrm{~mm}$. The papillary muscles of the right ventricle were grossly hypertrophied. There were no septal defects; the foramen ovale was not patent, the pulmonary valve orifice (circumference $8.5 \mathrm{~cm}$.), and the tricuspid valve ring (circumference $1 \mathrm{I} \cdot 2 \mathrm{~cm}$.) were dilated. Lung sections showed thickening of the arteries with much intimal proliferation, narrowing, and occlusion of the lumen. Lung parenchyma showed normal histology. Pulmonary artery section showed changes of atherosclerosis.

\section{Case 23}

Heart weighed $390 \mathrm{~g}$. and there was hypertrophy of the right ventricle. Thickness of the walls of 
the four chambers was as follows: right atrium $3 \mathrm{~mm}$., right ventricle Io $\mathrm{mm}$., left atrium $2 \mathrm{~mm}$., left ventricle $8 \mathrm{~mm}$. The right atrium was dilated, and the papillary muscles of the right ventricle were prominent. There were no septal defects and no patent foramen ovale. The pulmonary valve ring was dilated, and the pulmonary artery and its main branches were prominent. There was an enlarged mediastinal lymph node, and the hilar lymph nodes were prominent. Normal architecture was maintained in the lymph nodes which showed some areas of diffuse infiltration with eosinophils, but no filarial worms were seen. Lung histology revealed pulmonary oedema with scattered eosinophils, patchy fibrosis, and thickening of septa, with mononuclears, plasma cells, and clumps of eosinophils in the septa in some areas. A glomus-like structure was seen in the septum of the right lung. There was atherosclerosis of the pulmonary arteries, and some of the pulmonary veins showed thrombi.

\section{Treatment}

The patients were treated symptomatically. Antibiotics, bronchodilators (aminophylline), and oxygen inhalation were used in the presence of chest infection. Many patients were treated with long-term anticoagulant therapy in case there was an underlying thromboembolic process which was not detectable clinically. In view of eosinophilia and a possible filarial aetiology, patients with high eosinophil counts (over 2000) were given courses of diethyl carbamazine orally. There was a rapid fall in the eosinophil count but no significant clinical improvement.

\section{Discussion}

The cause of 'primary' pulmonary hypertension is by definition unknown. Among the many theories suggested were 'congenital abnormal broncho-pulmonary anastomoses' (Brinton, 1950), persistence of the foetal vascular pattern in the lung (Civin and Edwards, 1950), an overactive autonomic nervous system (Dresdale, Schultz, and Michtom, I95I), and recurrent, minute, symptomless pulmonary embolism (Wilcken, MacKenzie, and Goodwin, I960; Goodwin, Harrison, and Wilcken, 1963). Recent histological studies of the pulmonary vessels support the view that in the majority of cases, pulmonary hypertension is acquired (Heath and Edwards 1960). A familial variety of the disease has been described (Dresdale, Michtom, and Schultz, 1954), an association between pulmonary hypertension, Raynaud's phenomenon, and rheumatoid arthritis, implying that the disease may be due to a generalized collagen disease rather than to a local vascular disease confined to the lungs (Rawson and
Woske, 1960). Wood (1959) suggested that it was due to vascular spasm confined to the pulmonary vasculature, but did not specify the cause of the vasoconstriction.

While there is controversy as to the nature and cause of the disease, it seems certain that pulmonary hypertension need not always be the result of the same factors. There may be several varieties of the disease prevalent in different parts of the world. There are several features that suggest that the disease seen in Ceylon may be a separate disease entity with a different aetiology and pathogenesis.

The recent progress in cardiac catheterization in Ceylon has shown that 'primary' pulmonary hypertension has a much higher incidence here than in other parts of the world. In the past $2 \frac{1}{2}$ years, 37 patients were diagnosed in the Cardiology Unit in a consecutive series of 1000 patients investigated with cardiovascular disease of all types, an incidence of 3.7 per cent. Wood (1956) collected only 17 instances in almost Io years in a series of 10,000 cases, an incidence of only $0.17 \%$. A striking feature in the present series was the large number of male patients affected. Hitherto, the disease has been described predominantly in female patients, with a femaleto-male ratio of 4:I (Shepherd et al., 1957; Heath, Whitaker, and Brown, 1957; Evans, Short, and Bedford, 1957). In the present series the female-to-male ratio was $\mathrm{r} \cdot 5$ : I.

The clinical picture was remarkable for the severity of the pulmonary hypertension. Of 29 patients catheterized, 21 had pulmonary systolic pressures of $100 \mathrm{~mm} . \mathrm{Hg}$ and over, and I2 had pressures of I 120 and over. In Wood's series (1956) there was only one instance of a pressure over 100. Another striking feature noticed in this series and not previously reported was the presence of two clinical types, benign and malignant. In the benign type there was an insidious onset, a long history of disability, with gradual progression of the disease, and a low mortality. In the malignant type, the history was short, there was rapid progressive deterioration, no response to conventional therapy, and death occurred in a few months, often quite suddenly. The cause of this striking difference may be due to the patency of the foramen ovale in the benign type, which permitted shunting of blood from the right to the left side of the heart when the right side was overburdened. The foramen ovale was closed in all patients with the malignant type, and in no instance was the septum crossed during catheterization. By contrast many patients suffering from the benign type were found to have a patent foramen ovale. The presence of a patent foramen ovale 
which permits filling of the left heart and acts as a safety valve for the right ventricle (though at the expense of central cyanosis) helps to prolong life. This obviously has therapeutic implications and needs further investigation.

An association between 'primary' pulmonary hypertension and eosinophilia has been shown. The normal eosinophil count in Ceylon is regarded as 0 to 500 per cu. $\mathrm{mm}$. However, in hospital practice counts of up to $I, 000$ are not uncommon and are often caused by intestinal parasites. It was for this reason that the 2 control groups of patients admitted to the same unit and matched for age and sex were chosen (those with chronic rheumatic heart disease and congenital heart disease). Patients with 'primary' pulmonary hypertension had a significantly higher count which could not be accounted for by differences in severity or prevalence of intestinal parasitic infestation. None of the known causes of a raised eosinophil count was present: allergic conditions, infections such as chorea, erythema multiforme, and leprosy, skin diseases, diseases of the haemopoietic system, such as leukaemia, pernicious anaemia, and polycythaemia vera, fungal diseases, Hodgkin's disease, sarcoidosis, carcinoma, ulcerative colitis, drug sensitivity, visceral larva migrans, Loeffler's syndrome, polyarteritis nodosa, and tropical pulmonary eosinophilia. Even though 4 patients had eosinophil counts over 3,000 per cu.mm. and therefore fulfilled one of the criteria of tropical pulmonary eosinophilia, they did not have any respiratory symptoms such as a paroxysmal cough or bronchial asthma, a raised ESR, or radiological mottling in the lungs.

It has been established that tropical pulmonary eosinophilia is caused by filariasis. In 1960, Webb, Job, and Gault showed microfilariae in the lung, liver, and lymph nodes of a patient suffering from the disease. In 1966, Danaraj et al. showed degenerating microfilariae in eosinophilic granulomata in the lungs of these patients. He postulated that adult worms were probably alive and produced microfilariae which on reaching the lung were destroyed in an intense tissue reaction, producing the pulmonary symptoms and $x$-ray appearances characteristic of the disease; the hypereosinophilia, high level of complement-fixing antibodies to filaria protein, and the raised ESR being part of an immune hypersensitivity reaction, due to an abnormal host parasite relationship. In symptom-free filariasis, when the parasites and host are well adapted, there does not appear to be much tissue response as was shown by the low titres and poor antibody response, often with negative complement-fixation tests, absence of hypereosinophilia, and often normal erythrocyte sedimentation rates.

In patients with 'primary' pulmonary hypertension no microfilariae were found in the blood nor were they seen in the lungs in the two necropsies carried out. However, in one patient (Case 23) who had a strongly positive filaria complement-fixation test (titre $\mathrm{I} / \mathrm{I} 60$ ), there were scattered areas of eosinophilic infiltration in the lungs and a diffuse eosinophilic infiltration in a mediastinal lymph node. As these patients are poor surgical risks, thoracotomy and lung biopsy could not justifiably be done. The frequent association with eosinophilia and hypereosinophilia in 4 patients who did not have clinical tropical pulmonary eosinophilia, and the frequent finding of a sensitivity to filarial protein is highly suspicious, especially since the high eosinophilic counts responded to treatment with diethyl carbamazine. All 30 patients lived in areas where filariasis was endemic. Three patients gave a previous history of tropical pulmonary eosinophilia and two of clinical filariasis. In Ceylon filariasis affects both sexes alike. If 'primary' pulmonary hypertension has a filarial aetiology, this could be an explanation for the high incidence of the disease in male patients in this series. It is known that during acute phases of filariasis, microfilariae continue to be liberated from the adult worms and find their way into the pulmonary circulation. It is therefore conceivable that they embolize the pulmonary capillaries, setting into motion pulmonary hypertension in the same manner that minute pulmonary emboli consisting of blood clot or tumour particles do. The low titres obtained in most of these patients to the filaria complementfixation test may be due to a long time lag between the process of embolization and the development of pulmonary hypertension which in most patients is a relatively slow process.

Filarial worms are known to cause pulmonary hypertension in animals. Dissanaike and Paramananthan (196I) described a new filarial worm Brugia (Brugiella) buckleyi found in the right ventricle and pulmonary arteries of the Ceylon wild hare (Lepus nigricollis singhala). Electrocardiographic evidence of right ventricular hypertrophy was shown, and at necropsy gross hypertrophy and dilatation of the right ventricle with pulmonary infarction in the lungs (Jayasinghe, Fernando, and Dissanaike, 1964). Similar conditions occur in the dog where the filarial worm $D$. immitis is responsible (Detweiler, Hubben, and Patterson, 1960; Patterson and Luginbuhl, 1963). While 
Dissanaike and his co-workers make no mention of the histological changes that occur in the pulmonary vessels of the hare, Smith and Jones (1957) describe changes in the pulmonary vasculature of the dog very similar to the changes that occur in pulmonary hypertension in man. There is little doubt that filariasis is a cause of pulmonary hypertension in some animals. There is sufficient evidence to suspect that the same may be true in man. Since filariasis is endemic in certain areas and so widespread, it might account for the high incidence of this mysterious disease, 'primary' pulmonary hypertension, in Ceylon, where it is almost as common in the male as in the female patient and in whom there is often an associated eosinophilia.

We are grateful to Dr. Doris Peiris, Dr. C. H. Seneviratne, and Professor Gerald Cooray for their reports on the post-mortem material, Dr. M. Weerasena for reporting on the cine-angiograms and screening the patients, Dr. M. M. Ismail for carrying out the filarial complement-fixation tests, Professor A. S. Dissanaike for examining the blood samples for microfilaria, and Dr. C. Munasinghe for preparing Fig. 2.

We also thank Professor John Goodwin and Dr Richard Emanuel who very kindly corrected the script.

\section{References}

Brinton, W. D. (1950). Primary pulmonary hypertension. British Heart fournal, 12, 305.

Civin, W. H., and Edwards, J. E. (I950). Pathology of pulmonary vascular tree: I. A comparison of the intrapulmonary arteries in the Eisenmenger complex and in stenosis of ostium infundibuli associated with biventricular origin of the aorta. Circulation, 2, 545 .

Danaraj, T. J. (1957). Tropical pulmonary eosinophilia. British Medical fournal, 2, 16r.

—, da Silva, L. S., and Schacher, J. F. (1957). The filarial complement fixation test in eosinophilic lung. Proceedings of the Alumni Association, Malaya, 10, 109.

- Pacheco, G., Shanmugaratnam, K., and Beaver, P. C. (1966). The etiology and pathology of eosinophilic lung. American fournal of Tropical Medicine and Hygiene, $15,183$.

Detweiler, D. K., Hubben, K., and Patterson, D. F. (1960). Survey of cardiovascular disease in dogs: preliminary report on the first 1,000 dogs screened. American fournal of Veterinary Research, 21, 329.

Dissanaike, A. S., and Paramananthan, D. C. (196I). On Brugia (Brugiella subgen. nov). buckleyi. n.sp., from the heart and blood vessels of the Ceylon Hare. Fournal of Helminthology, 35, 209.

Dresdale, D. T., Michtom, R. J., and Schultz, M. (1954). Recent studies in primary pulmonary hypertension, including pharmacodynamic observations on pulmonary vascular resistance. Bulletin of the New York Academy of Medicine, 30, 195.

- Schultz, M., and Michtom, R. J. (195I). Primary pulmonary hypertension. I. Clinical and hemodynamic study. American fournal of Medicine, II, 686.

Evans, W., Short, D. S., and Bedford, D. E. (1957). Solitary pulmonary hypertension. British Heart Fournal, 19, 93.

Goodwin, J. F., Harrison, C. V., and Wilcken, D. E. L. (1963). Obliterative pulmonary hypertension and thrombo-embolism. British Medical fournal, r, 701 .

Heath, D., and Edwards, J. E. (1960). Configuration of elastic tissue of pulmonary trunk in idiopathic pulmonary hypertension. Circulation, 21, 59.

- Whitaker, W., and Brown, J. W. (I957). Idiopathic pulmonary hypertension. British Heart fournal, 19, 83.

Hollister, R. M., and Goodwin, J. F. (1963). The electrocardiogram in cardiomyopathy. British Heart fournal, 25, 357.

Jayasinghe, J. B., Fernando, S. D. A., and Dissanaike, A. S. (1964). Electrocardiographic evidence of cardiac hypertrophy in a hare infected with the filarial worm Brugia (Brugiella) buckleyi. Annals of Tropical Medicine and Parasitology, 58, 328.

Jayewardena, L. G., and Wijayaratnam, Y. (I968). The fluorescent antibody test in the serological diagnosis of the causative organisms of tropical eosinophilia and filariasis. Journal of Helminthology, 42, 57.

Patterson, D. F., and Luginbuhl, H. R. (1963). Clinico-pathologic Conference. Fournal of the American Veterinary Medical Association, 143, 619.

Rawson, A. J., and Woske, H. M. (1960). A study of etiologic factors in so-called primary pulmonary hypertension. Archives of Internal Medicine, 105, 233.

Shepherd, J. T., Edwards, J. E., Burchell, H. B., Swan, H. J. C., and Wood, E. H. (1957). Clinical, physiological, and pathological considerations in patients with idiopathic pulmonary hypertension. British Heart fournal, 19, 70.

Smith, H. A., and Jones, T. C. (1957). Veterinary Pathology. Henry Kimpton, London.

Wade, G., and Ball, J. (1957). Unexplained pulmonary hypertension. Quarterly fournal of Medicine, 50, (n.s. 26), 83.

Webb, J. K. B., Job, C. K., and Gault, E. W. (1960). Tropical eosinophilia; demonstration of microfilariae in lung, liver, and lymph-nodes. Lancet, $\mathbf{r}$, 835.

Wilcken, D. E. L., MacKenzie, K. M., and Goodwin, J. F. (1960). Anticoagulant treatment of obliterative pulmonary hypertension. Lancet, 2, 78r.

Wood, P. (1956). Diseases of the Heart and Circulation, 2nd ed. Eyre and Spottiswoode, London.

(1959). Pulmonary hypertension. Modern Concepts of Cardiovascular Disease, 28, 513. 
AP PENDIX I Haemodynamic data in 29 patients suffering from 'primary' pulmonary hypertension

\begin{tabular}{|c|c|c|c|c|c|c|c|c|c|c|c|c|c|c|}
\hline $\begin{array}{l}\text { Case } \\
\text { No. }\end{array}$ & $\begin{array}{l}R A \\
\text { 'A wave' }\end{array}$ & $\begin{array}{l}R A \\
\text { mean }\end{array}$ & $\begin{array}{l}\text { Pressures (n } \\
R V\end{array}$ & $\begin{array}{c}\operatorname{mm} . H g \\
P A\end{array}$ & $\begin{array}{l}P A \\
\text { mean }\end{array}$ & $\begin{array}{l}P C W \text { or } \\
L A \\
\text { ' } A \text { wave' }\end{array}$ & $P V$ & $\begin{array}{l}\text { FA or } \\
\text { systemic } \\
B P\end{array}$ & $\begin{array}{l}O x y \\
F A\end{array}$ & $\begin{array}{c}\text { gen sa } \\
P A \\
\text { or } \\
R V\end{array}$ & $\begin{array}{l}\text { turation } \\
\mathrm{Hb} \\
(\mathrm{g} . / 100 \mathrm{ml} .)\end{array}$ & $\begin{array}{l}\text { Cardiac output } \\
\text { (l./min.) }\end{array}$ & $\begin{array}{l}\text { Pulmonary } \\
\text { vasc. resist. } \\
\text { (units) }\end{array}$ & $\begin{array}{l}\text { Foramen } \\
\text { ovale }\end{array}$ \\
\hline $\mathbf{I}$ & 7 & 3 & $140,0,8$ & $140 / 72$ & 82 & 6 & 6 & $100 / 70$ & 82 & 56 & $12 \cdot 9$ & $4 \cdot 6$ & 20 & Open \\
\hline 2 & 5 & 2 & & $100 / 50$ & 56 & - & 一 & $140 / 100$ & 90 & 52 & II $\cdot 0$ & 3.6 & 16 & Closed \\
\hline 3 & 4 & 0 & $152,4,8$ & $144 / 48$ & 80 & 5 & 6 & $105 / 80$ & 87 & 71 & $12 \cdot 2$ & $\begin{array}{l}\mathrm{O}_{2} \text { consumption } \\
\text { not determined }\end{array}$ & - & Open \\
\hline 4 & 5 & 2 & $100,0,4$ & $100 / 40$ & 56 & 5 & - & $100 / 70$ & 90 & 62 & $13 \cdot 8$ & $3 \cdot 8$ & 15 & Closed \\
\hline 5 & 8 & 4 & $140,0,12$ & $140 / 112$ & 92 & 5 & 一 & $110 / 80$ & 90 & 63 & 15.5 & $4 \cdot 8$ & 19 & Open \\
\hline 6 & 5 & I & $120,0,4$ & $120 / 60$ & 72 & 2 & - & $120 / 80$ & 95 & 73 & $12 \cdot 4$ & $5 \cdot 0$ & 14 & Closed \\
\hline 7 & 5 & 2 & $112,0,4$ & $112 / 60$ & 64 & 4 & 4 & $96 / 56$ & 82 & 65 & 15.6 & $3 \cdot 0$ & 21 & Open \\
\hline 8 & 10 & 5 & $120,0,8$ & $120 / 64$ & 78 & 7 & 5 & $90 / 70$ & 79 & 46 & $12 \cdot 4$ & $2 \cdot 8$ & 28 & Open \\
\hline 9 & II & 6 & $120,0,16$ & $120 / 64$ & 74 & - & - & $104 / 72$ & 89 & 57 & $15 \cdot 6$ & 3.9 & 16 & Closed \\
\hline 10 & 15 & 8 & $96,0,8$ & $96 / 44$ & 60 & 5 & 一 & $120 / 80$ & 95 & 61 & 14.3 & 4.6 & 13 & Closed \\
\hline II & 6 & 3 & $112,0,6$ & $112 / 64$ & 68 & - & 一 & $116 / 80$ & 92 & 62 & $12 \cdot 2$ & $4 \cdot 0$ & 17 & \\
\hline 12 & 12 & 7 & $96,0,4$ & $96 / 44$ & 58 & 4 & 一 & $120 / 70$ & 89 & 52 & $9 \cdot I$ & $2 \cdot 4$ & 24 & Open \\
\hline 13 & 15 & II & $96,8,24$ & $96 / 44$ & 60 & - & 一 & $100 / 80$ & 90 & 48 & 13.0 & $2 \cdot I$ & 29 & Closed \\
\hline 14 & 14 & 9 & $100,5,8$ & Not ente & ered & 9 & 一 & $120 / 80$ & 86 & 55 & $12 \cdot 6$ & $4 \cdot 0$ & - & Open \\
\hline 15 & 5 & I & $120,0,4$ & $120 / 60$ & 72 & 5 & 4 & $120 / 80$ & 95 & 77 & $12 \cdot 2$ & $\mathrm{O}_{2}$ consumption & - & Closed \\
\hline 16 & 8 & 4 & $85,0,4$ & $88 / 48$ & 56 & - & $\underline{4}$ & $112 / 80$ & 90 & 77 & 14.8 & not determined & - & Closed \\
\hline $\begin{array}{l}17 \\
18\end{array}$ & Exp & $\begin{array}{l}\text { I2 } \\
\text { ired } b\end{array}$ & $\begin{array}{l}112,6,16 \\
\text { before cathet }\end{array}$ & $\begin{array}{l}100 / 48 \\
\text { terization }\end{array}$ & 56 & 8 & 一 & $110 / 80$ & 85 & 57 & $13 \cdot 8$ & $4 \cdot 3$ & I3 & Closed \\
\hline 19 & 5 & 3 & $104,0,4$ & $104 / 64$ & 64 & 一 & 一 & $120 / 80$ & $9 I$ & 78 & $14 \cdot 8$ & $5 \cdot 0$ & 13 & $?$ \\
\hline 20 & 12 & 8 & $96,0,8$ & $96 / 52$ & 60 & - & - & $110 / 85$ & 91 & $5 \mathrm{I}$ & $12 \cdot 8$ & $2 \cdot 8$ & 21 & $?$ \\
\hline 21 & 22 & 14 & $88,4,16$ & $80 / 40$ & 40 & 8 & 一 & $110 / 80$ & 91 & 48 & II $\cdot 0$ & $2 \cdot I$ & 19 & Open \\
\hline 22 & 5 & I & $96,0,4$ & $96 / 40$ & 56 & 4 & 5 & $112 / 56$ & 88 & 44 & 10.7 & $3 \cdot 2$ & 14 & Closed \\
\hline 23 & I0 & 5 & $168,8,16$ & $168 / 60 \mathrm{I}$ & 108 & - & - & $96 / 80$ & 97 & 67 & 12.9 & $3 \cdot 1$ & 35 & Closed \\
\hline 24 & 14 & 9 & $120,0,12$ & $120 / 56$ & 72 & 3 & 3 & $112 / 80$ & 90 & 51 & $15 \cdot 1$ & $3 \cdot 8$ & 19 & Closed \\
\hline 25 & 15 & 9 & $200,8,16$ & $220 / 1121$ & 160 & 8 & - & $104 / 80$ & 86 & 65 & $17 \cdot 6$ & $3 \cdot 6$ & 44 & Open \\
\hline 26 & 10 & 3 & $130,6,08$ & $136 / 48$ & 80 & 0 & 0 & $100 / 70$ & 95 & 73 & 10.9 & 4.6 & 17 & Closed \\
\hline 27 & 20 & 16 & $144,8,24$ & Not ente & ered & - & - & I $10 / 90$ & 92 & 67 & 13.3 & 4.5 & - & Closed \\
\hline 28 & 5 & 0 & 128,0 & $120 / 72$ & 88 & 6 & 5 & $110 / 85$ & 95 & 76 & $12 \cdot 2$ & 4.4 & 20 & Open \\
\hline 29 & 4 & 0 & $104,0,8$ & $104 / 48$ & 72 & 3 & I & $110 / 80$ & 90 & 67 & 13.9 & $2 \cdot 7$ & 23 & Open \\
\hline 30 & 4 & 2 & $88,0,4$ & $88 / 40$ & 52 & 2 & 2 & $110 / 80$ & 91 & 78 & $11 \cdot 7$ & $\begin{array}{l}\mathrm{O}_{2} \text { consumption } \\
\text { not determined }\end{array}$ & - & Open \\
\hline
\end{tabular}

RA, right atrium; RV, right ventricle; PA, pulmonary artery; LA, left atrium; PCW, pulmonary capillary wedge; FA, femoral artery; PV, pulmonary vein. 
A PPENDIX II Clinical data in patients with 'primary' pulmonary hypertension

\begin{tabular}{|c|c|c|c|c|c|c|c|c|c|c|c|}
\hline \multicolumn{3}{|c|}{$\begin{array}{l}\text { Case No., age (yr.), } \\
\text { and sex }\end{array}$} & \multirow{2}{*}{$\begin{array}{l}\begin{array}{l}\text { Duration of } \\
\text { illness (yr.) }\end{array} \\
8\end{array}$} & \multirow{2}{*}{$\frac{\text { Dyspnoea* }}{++}$} & \multirow{2}{*}{$\begin{array}{l}\text { Palpitation } \\
++\end{array}$} & \multirow{2}{*}{$\begin{array}{l}\begin{array}{l}\text { Undue } \\
\text { fatigue }\end{array} \\
0\end{array}$} & \multirow{2}{*}{$\begin{array}{l}\text { Syncope } \\
+\end{array}$} & \multirow{2}{*}{$\begin{array}{l}\text { Angina } \\
0\end{array}$} & \multirow{2}{*}{$\begin{array}{l}\text { Haemoptysis } \\
0\end{array}$} & \multirow{2}{*}{$\begin{array}{l}\text { Right heart } \\
\text { failuret } \\
\circ\end{array}$} & \multirow{2}{*}{$\begin{array}{l}\text { Weight (kg.) } \\
38 \cdot 1\end{array}$} \\
\hline $\mathbf{I}$ & 26 & $\mathbf{F}$ & & & & & & & & & \\
\hline 2 & 30 & $\mathbf{F}$ & 6 & ++ & + & + & 0 & + & 0 & 0 & $55 \cdot 8$ \\
\hline 3 & 23 & $\mathbf{F}$ & 5 & ++ & + & + & + & 0 & 0 & 0 & $30 \cdot 8$ \\
\hline 4 & 23 & $\mathbf{F}$ & $6 / 12$ & +++ & + & + & + & + & 0 & ++ & 53.5 \\
\hline 5 & I7 & $\mathbf{F}$ & I5 & ++ & 0 & 0 & 0 & 0 & + & 0 & $37 \cdot 7$ \\
\hline 6 & 22 & $\mathbf{F}$ & 2 & ++ & + & + & + & 0 & 0 & + & $4 I \cdot 3$ \\
\hline 7 & 34 & $\mathbf{F}$ & 6 & +++ & + & + & 0 & + & 0 & + & $43 \cdot 0$ \\
\hline 8 & 15 & $\mathbf{F}$ & 2 & ++ & + & + & 0 & 0 & 0 & 0 & $45 \cdot 5$ \\
\hline 9 & 22 & $\mathbf{F}$ & $2 / 12$ & +++ & 0 & + & + & + & 0 & ++ & 24.9 \\
\hline I0 & 42 & $\mathbf{F}$ & $2 / 12$ & +++ & + & + & + & + & 0 & $+t$ & $49 \cdot 9$ \\
\hline II & 17 & $\mathbf{F}$ & Io & ++ & + & 0 & + & 0 & 0 & 0 & $36 \cdot 7$ \\
\hline 12 & 28 & $\mathbf{F}$ & 14 & ++ & + & 0 & 0 & 0 & 0 & + & $40 \cdot 8$ \\
\hline 13 & 24 & $\mathbf{F}$ & $6 / 12$ & +++ & + & + & + & + & 0 & ++ & $46 \cdot 7$ \\
\hline 14 & $6 I$ & $\mathbf{F}$ & 35 & ++ & + & + & + & 0 & + & 0 & 35.4 \\
\hline 15 & 28 & $\mathbf{F}$ & $6 / 12$ & ++ & 0 & 0 & + & 0 & + & + & 54.4 \\
\hline 16 & 22 & $\mathbf{M}$ & $6 / 12$ & +++ & + & + & + & + & 0 & $+t$ & $43 \cdot 5$ \\
\hline 17 & 39 & $\mathbf{M}$ & I $\frac{1}{2}$ & ++ & + & 0 & + & 0 & 0 & + & $67 \cdot 1$ \\
\hline 18 & 21 & $\mathbf{M}$ & $4 / 12$ & $+++t$ & + & + & + & + & + & ++ & $47 \cdot 2$ \\
\hline 19 & 17 & $\mathbf{M}$ & 12 & ++ & + & + & 0 & 0 & 0 & 0 & $42 \cdot 2$ \\
\hline 20 & 33 & $\mathbf{M}$ & $I \frac{1}{2}$ & ++ & + & + & 0 & 0 & 0 & 0 & $38 \cdot 5$ \\
\hline 21 & 9 & $\mathbf{M}$ & 7 & ++ & + & + & 0 & 0 & 0 & + & $24 \cdot 9$ \\
\hline 22 & 50 & $\mathbf{M}$ & 3 & ++ & + & + & + & + & 0 & 0 & 39.5 \\
\hline 23 & 21 & $\mathbf{M}$ & $3 / 12$ & ++ & + & + & + & + & + & ++ & $35 \cdot 8$ \\
\hline 24 & 42 & $M$ & 5 & ++ & + & + & + & 0 & 0 & 0 & 63.5 \\
\hline 25 & 23 & $\mathbf{M}$ & II & ++ & 0 & 0 & + & 0 & 0 & 0 & 39.9 \\
\hline 26 & 40 & $\mathbf{M}$ & $I \frac{1}{2}$ & ++ & + & + & + & + & 0 & + & $38 \cdot 1$ \\
\hline 27 & 38 & $\mathbf{M}$ & $\mathbf{I}$ & +++ & + & + & + & + & + & ++ & $59 \cdot 0$ \\
\hline 28 & 15 & $\mathbf{F}$ & 12 & ++ & + & 0 & 0 & 0 & 0 & 0 & 35.4 \\
\hline 29 & 32 & $\mathbf{F}$ & 2 & ++ & + & + & + & 0 & 0 & 0 & $38 \cdot I$ \\
\hline 30 & 16 & $\mathbf{F}$ & 2 & ++ & + & 0 & 0 & + & 0 & 0 & $36 \cdot 7$ \\
\hline
\end{tabular}

* Dyspnoea on exertion: + mild; ++ moderate +++ severe; ++++ present at rest.

+ Right heart failure: + mild; ++ severe.

¥ Auscultation - pulmonary area: I narrowly split 2nd sound, 2nd component loud; II early ejection systolic click; III short ejection systolic murmur; IV longer systolic murmur, early diastolic murmur; V prolonged early diastolic murmur. 
Cyanosis and fugular venous Auscultation $\ddagger$ clubbing of fingers fugular venous Auscultation $\ddagger$

Pulm. Tricusp.
area area
Systemic blood PA or $R V$

pressure (mm.Hg) pressure (mm.Hg) hypertension

\begin{tabular}{|c|c|c|c|c|c|c|c|}
\hline+ & 5 & IV & II & $120 / 80$ & $140 / 72$ & Alive & Benign \\
\hline+ & 6 & II & III & $130 / 90$ & $100 / 50$ & Dead (died during catheterization) & Benign \\
\hline 0 & ? & IV & II & $130 / 80$ & $144 / 48$ & Alive & Benign \\
\hline o & 4 & III & IV & $100 / 40$ & $100 / 40$ & Dead & Malignant \\
\hline+ & o & II & II & $120 / 80$ & $140 / 112$ & Alive & Benign \\
\hline 0 & 6 & I & I & $120 / 80$ & $120 / 60$ & Alive & Benign \\
\hline+ & I0 & III & II & $120 / 90$ & $112 / 60$ & Alive & Benign \\
\hline 0 & 6 & II & II & $90 / 70$ & $120 / 64$ & Alive & Benign \\
\hline 0 & 8 & IV & III & $130 / 100$ & $120 / 64$ & Alive (severely disabled) & Malignant \\
\hline o & 6 & II & III & $140 / 90$ & $96 / 44$ & Dead & Malignant \\
\hline+ & 3 & III & I & $100 / 80$ & $112 / 64$ & Alive & Benign \\
\hline ○ & 6 & IV & II & $130 / 70$ & $96 / 44$ & Alive & Benign \\
\hline 0 & 6 & II & III & $100 / 80$ & $96 / 44$ & Dead & Malignant \\
\hline 0 & 5 & $\mathbf{V}$ & I & $130 / 100$ & $100,5,8(\mathrm{RV})$ & Alive & Benign \\
\hline 0 & 4 & II & I & $130 / 80$ & $120 / 60$ & Alive & Benign \\
\hline 0 & 5 & III & IV & $110 / 80$ & $88 / 4$ & Dead & Malignant \\
\hline 0 & 8 & III & II & $110 / 80$ & $100 / 48$ & Alive & Benign \\
\hline 0 & 5 & II & IV & $100 / 80$ & - & Dead & Malignant \\
\hline 0 & 3 & IV & III & $120 / 80$ & $104 / 64$ & Alive & Benign \\
\hline 0 & ro & II & II & $110 / 80$ & $96 / 52$ & Alive & Benign \\
\hline 0 & 6 & I & II & $120 / 70$ & $80 / 40$ & Alive & Benign \\
\hline 0 & 6 & II & II & $130 / 80$ & $96 / 40$ & Alive & Benign \\
\hline 0 & 8 & II & II & $90 / 70$ & $168 / 60$ & Dead & Malignant \\
\hline+ & 8 & II & I & $110 / 90$ & $120 / 56$ & Alive & Benign \\
\hline+ & 3 & V & I & $100 / 80$ & $220 / 112$ & Alive & Benign \\
\hline 0 & 8 & I & II & $100 / 70$ & $136 / 48$ & Alive & Benign \\
\hline 0 & 13 & II & IV & $110 / 90$ & $144,8,24$ & Dead & Malignant \\
\hline o & 0 & II & I & $110 / 85$ & $120 / 72$ & Alive & Benign \\
\hline 0 & 4 & II & I & $110 / 80$ & $105 / 68$ & Alive & Benign \\
\hline 0 & 0 & II & I & $110 / 80$ & $88 / 40$ & Alive & Benign \\
\hline
\end{tabular}

Present status classification of pulmonary 
APPENDIX II I Comparison of absolute eosinophil counts, Hb tests for filariasis, ESR, and pulmonary artery pressure in patients with ( $I$ ) 'primary' pulmonary hypertension, (2) tropical pulmonary eosinophilia, and (3) symptom-free filariasis

\begin{tabular}{|c|c|c|c|c|c|c|c|c|c|c|c|c|}
\hline & $\begin{array}{l}\text { Case } \\
\text { No., }\end{array}$ & age, & and sex, & $\begin{array}{l}\text { Absolute } \\
\text { eosinophil } \\
\text { count }\end{array}$ & $\begin{array}{l}H b \\
(g . / 100 \mathrm{ml} .)\end{array}$ & $\begin{array}{l}\text { PA blood } \\
\text { for } \\
\text { microfilaria }\end{array}$ & $\begin{array}{l}\text { Thick film } \\
\text { for } \\
\text { microfilaria }\end{array}$ & $\begin{array}{l}\text { Venous } \\
\text { blood for } \\
\text { microfilaria }\end{array}$ & $\begin{array}{l}\text { FCFT } \\
\text { (titre) }\end{array}$ & $F A T$ & $\begin{array}{l}E S R \\
(I s t h r .) \\
(\mathrm{mm} .)\end{array}$ & $\begin{array}{l}\text { PA pressure } \\
(\mathrm{mm} . \mathrm{Hg})\end{array}$ \\
\hline \multirow{8}{*}{$\begin{array}{l}\text { Tropical } \\
\text { pulmonary } \\
\text { eosinophilia }\end{array}$} & 31 & 23 & $\mathrm{~F}$ & 9638 & $9 \cdot 6$ & $-v e$ & -ve & $-\mathrm{ve}$ & +1 in 40 & - ve & 22 & $30 / 8$ \\
\hline & 32 & 30 & $\mathbf{M}$ & 20000 & $9 \cdot 6$ & -ve & - ve & - ve & $+I$ in 40 & - ve & 6 & $28 / 12$ \\
\hline & 33 & 25 & $\mathbf{M}$ & 12070 & II 7 & -ve & -ve & -ve & $+I$ in 80 & -ve & 20 & $28 / 12$ \\
\hline & 34 & 60 & $\mathbf{M}$ & 11950 & 10.9 & - ve & $-v e$ & -ve & $+I$ in 40 & +ve & 24 & $24 / 10$ \\
\hline & 35 & 29 & $M$ & 14280 & $12 \cdot 2$ & -ve & -ve & -ve & +1 in 160 & - ve & 51 & $28 / 10$ \\
\hline & 36 & 47 & $\mathbf{M}$ & 10912 & $11 \cdot 3$ & -ve & $-v e$ & -ve & $+I$ in 40 & +ve & 28 & $24 / 10$ \\
\hline & 37 & 6 & $\mathrm{~F}$ & 8554 & $9 \cdot 5$ & -ve & -ve & -ve & $+I$ in 80 & +ve & 30 & $30 / 10$ \\
\hline & 38 & 15 & $\mathbf{F}$ & 5719 & 10.1 & - ve & $-v e$ & -ve & $+I$ in 40 & $-v e$ & 64 & $26 / 8$ \\
\hline \multirow{8}{*}{$\begin{array}{l}\text { Symptom-free } \\
\text { filariasis }\end{array}$} & 39 & 46 & $\mathbf{F}$ & 1750 & $9 \cdot I$ & $+v e$ & $+\mathrm{ve}$ & $+\mathrm{ve}$ & -ve & -ve & 42 & $20 / 6$ \\
\hline & 40 & 17 & $\mathbf{F}$ & 612 & 10.4 & $-v e$ & $+\mathrm{ve}$ & $+\mathrm{ve}$ & - ve & -ve & 13 & $20 / 6$ \\
\hline & $4 I$ & 24 & $\mathbf{M}$ & 3650 & $11 \cdot 3$ & $+v e$ & +ve & $+\mathrm{ve}$ & -ve & -ve & 5 & $22 / 8$ \\
\hline & 42 & 17 & $\mathbf{M}$ & 394 & $11 \cdot 7$ & $+\mathrm{ve}$ & $+\mathrm{ve}$ & $+\mathrm{ve}$ & -ve & -ve & 21 & $26 / 0$ \\
\hline & 43 & 27 & $\mathbf{M}$ & 784 & 13.9 & $+v e$ & $+\mathrm{ve}$ & tve & -ve & -ve & 6 & $32 / 10$ \\
\hline & 44 & 30 & $\mathbf{M}$ & 194 & 13.0 & $+\mathrm{ve}$ & +ve & $+\mathrm{ve}$ & -ve & -ve & 3 & $22 / 8$ \\
\hline & 45 & 40 & $\mathbf{M}$ & 836 & $12 \cdot 2$ & -ve & +ve & $+\mathrm{ve}$ & - ve & - ve & 4 & $24 / 10$ \\
\hline & 46 & 15 & $\mathbf{F}$ & 712 & 10.9 & +ve & +ve & $+\mathrm{ve}$ & +1 in 20 & -ve & 20 & $24 / 10$ \\
\hline \multirow{15}{*}{$\begin{array}{l}\text { 'Primary' } \\
\text { pulmonary } \\
\text { hypertension }\end{array}$} & 5 & 17 & $\mathbf{F}$ & 716 & 15.5 & -ve & $-v e$ & $-v e$ & $+I$ in 5 & - ve & 10 & $140 / 112$ \\
\hline & 7 & 34 & $\mathbf{F}$ & 1672 & 15.6 & -ve & - ve & -ve & - ve & -ve & 5 & I I $2 / 64$ \\
\hline & 8 & 15 & $\mathbf{F}$ & 780 & $12 \cdot 4$ & -ve & - ve & -ve & $+\mathrm{I}$ in 10 & $+\mathrm{ve}$ & 9 & $120 / 64$ \\
\hline & 9 & 22 & $\mathrm{~F}$ & 7497 & $15 \cdot 6$ & -ve & - ve & -ve & $+I$ in 5 & -ve & 10 & $120 / 64$ \\
\hline & 10 & 42 & $\mathrm{~F}$ & 560 & 14.3 & -ve & -ve & - ve & - ve & -ve & 19 & $96 / 44$ \\
\hline & II & 17 & $\mathrm{~F}$ & 3483 & $12 \cdot 2$ & -ve & -ve & -ve & $+I$ in 80 & - ve & I0 & II $2 / 64$ \\
\hline & 13 & 24 & $\mathrm{~F}$ & 9898 & 13.0 & -ve & - ve & -ve & $+I$ in 80 & - ve & 4 & $96 / 44$ \\
\hline & I4 & 61 & $\mathrm{~F}$ & 846 & 12.6 & -ve & - ve & $-\mathrm{ve}$ & -ve & $+\mathrm{ve}$ & 3 & $100 / 80$ \\
\hline & 15 & 28 & $\mathrm{~F}$ & 118 & $12 \cdot 2$ & -ve & -ve & -ve & -ve & -ve & - & $120 / 60$ \\
\hline & 17 & 39 & M & 896 & 13.2 & -ve & -ve & -ve & - ve & +ve & - & $100 / 48$ \\
\hline & 22 & 50 & $\mathbf{M}$ & 712 & $10 \cdot 7$ & $-v e$ & -ve & $-v e$ & $+I$ in 10 & - ve & 8 & $96 / 40$ \\
\hline & 23 & $2 I$ & $M$ & 336 & $12 \cdot 9$ & $-v e$ & -ve & -ve & +1 in 160 & - ve & 4 & $168 / 80$ \\
\hline & 24 & 42 & $\mathbf{M}$ & 1008 & $15 \cdot 1$ & -ve & -ve & -ve & +1 in 70 & -ve & 4 & $120 / 56$ \\
\hline & 25 & 23 & $\mathbf{M}$ & 1160 & $17 \cdot 6$ & -ve & -ve & -ve & $+I$ in 10 & -ve & 0 & $220 / 112$ \\
\hline & 26 & 40 & $\mathbf{M}$ & 688 & 10.9 & -ve & - ve & -ve & -ve & -ve & 14 & $136 / 48$ \\
\hline
\end{tabular}

PA, pulmonary artery; $F C F \Gamma$, tilaria complement-tnxation test; FAT, fluorescent antibody test. 